\title{
Therapeutic efficacy of artemether- lumefantrine in the treatment of uncomplicated Plasmodium falciparum malaria in Ethiopia: a systematic review and meta-analysis
}

Mohammed Biset Ayalew

\begin{abstract}
Background: As Ethiopia is one of the sub-Saharan countries with a great burden of malaria the effectiveness of first line anti-malarial drugs is the major concern. The aim of this study was to synthesize the available evidence on the efficacy of artemether-lumefantrine in the treatment of uncomplicated Plasmodium falciparum malaria in Ethiopia. This was done by performing a meta-analysis of recent studies conducted in the country on this topic.

Methods: Studies published between January 2010 and January 2017 that reported on the efficacy of artemetherlumefantrine in the treatment of $P$. falciparum malaria in Ethiopian patients were searched for using the PubMed and Google Scholar databases. Ten prospective single-arm cohort studies that followed patients for 28-42 days were included in this analysis. All of the included studies were deemed to be of high quality.

Results: Ten studies involving 1179 patients that were eligible for meta-analysis were identified. At recruitment, the average parasite count per patient was $12981 / \mu$ of blood. On the third day of treatment, $96.7 \%$ and $98.5 \%$ of the study subjects become fever-free and parasite-free, respectively. Based on the per protocol analysis, the cure rate after use of artemether-lumefantrine was $98.2 \%$ (polymerase chain reaction corrected) and $97.01 \%$ (polymerase chain reaction uncorrected) after 28 days of follow-up. The reinfection rate within 28 days was $1.1 \%$ and the recrudescence rate was $1.9 \%$.

Conclusions: This review found that the cure rate for uncomplicated $P$. falciparum malaria using artemetherlumefantrine in Ethiopia is still high enough to recommend the drug as a first-line agent. There should be careful periodic monitoring of the efficacy of this drug, as treatment failure may occur due to resistance, sub-therapeutic levels that may occur due to non-adherence, or inadequate absorption.
\end{abstract}

Keywords: Efficacy, Artemether-lumefantrine, Plasmodium falciparum, Ethiopia, Meta-analysis 


\section{Multilingual abstracts}

Please see Additional file 1 for translations of the abstract into the five official working languages of the United Nations.

\section{Background}

Malaria is one of the major public health problems in the world. Its burden is very high in Sub-Saharan Africa, where about $90 \%$ of all malaria deaths occur [1]. Each minute, six people in Africa die because of malaria [1, 2]. Malaria is also one of the leading causes of avoidable deaths in pregnant women and children in developing countries [2].

Malaria is an important communicable disease affecting large numbers of people in Ethiopia. About $68 \%$ of the Ethiopian population lives in high-risk malaria areas [3]. The common malaria-causing species in Ethiopia are Plasmodium falciparum and P. vivax; roughly $60 \%$ of malaria cases in the country are due to the former $[4,5]$. An estimated death rate of severe malaria caused by $P$. falciparum in Ethiopia is about 33\% in children below 12 years of age and $10 \%$ in hospitalized adults [6].

Early diagnosis and timely treatment of malaria with an effective drug is an important strategy to control the disease [7]. However, the emergence of antimalarial drug resistance is one of the challenges towards controlling malaria [1]. In the early 1990s, a chloroquine-resistant $P$. falciparum strain was the main threat to malaria prevention and control in Ethiopia [8]. A failure rate of above $85 \%$ for chloroquine was reported in the late 1990s. This event triggered the change of first-line treatment to sulphadoxine-pyrimethamine in 1998 [9, 10]. However, a study conducted on sulphadoxine-pyrimethamine throughout the country in 2003 reported a $72 \%$ treatment failure rate [11]. After the occurrence of a large-scale malaria epidemic in 2003 [12] and the concomitant recognition of widespread resistance to sulphadoxine-pyrimethamine $[11,13]$, the Federal Ministry of Health of Ethiopia adopted artemether-lumefantrine (AL) as the first-line treatment of uncomplicated P. falciparum malaria in 2004 [14]. At that time, the baseline efficacy of AL was $99.1 \%$, which showed a treatment failure rate of under $1 \%$ [11].The commonly used brand name of a drug containing AL in Ethiopia is coartem.

The World Health Organization (WHO) recommends above $90 \%$ parasitological and clinical curative rates for an antimalarial drug to be approved as a first-line agent [15]. There are many studies conducted in different parts of the world that show that AL fulfills this criterion [16-18]. However, regardless of these reports, studies conducted in Thailand, Japan, Kenya, Zanzibar, and Cambodia have indicated the emergency of treatment failure and an evolvement of a drug-resistant parasite against AL [19-24]. An ongoing monitoring of first-line therapies is very important in order to ensure the use of effective drugs and to maintain the progress made to date in decreasing malaria morbidity and mortality [25].

The WHO recommends that the efficacy of first-line antimalarial drugs should be checked at least every two years [15]. As Ethiopia is one of the Sub-Saharan countries with a great burden of malaria, the effectiveness of this first-line drug is of major concern. The purpose of this review was therefore to synthesize the available evidence on the efficacy of AL in the treatment of uncomplicated P. falciparum malaria in Ethiopia.

\section{Methodology}

\section{Search strategy}

Literature published between January 2010 and January 2017 that assessed the efficacy of AL in the treatment of uncomplicated $P$. falciparum malaria in Ethiopia was searched for using the online databases PubMed (https:// www.ncbi.nlm.nih.gov/pubmed/) and Google Scholar (https://scholar.google.com/).

The search was conducted by combining the following words: 'efficacy', 'therapeutic efficacy', 'artemether-lumefantrine', 'Coartem,'cohort', 'in vivo', 'Plasmodium falciparum malaria, 'antimalarial drug', and 'Ethiopia'. Selected reference lists of retrieved articles were also searched manually using Google.

\section{Article selection}

The author reviewed all of the identified articles in order to assess eligibility for inclusion based on predefined criteria. Studies done to assess the efficacy of AL on P. falciparum mono-infected Ethiopian patients and which were published between January 2010 and January 2017 were included in this review. Studies done on nonhuman subjects and articles of which the full text could not be obtained were excluded.

\section{Quality assessment}

Validity and methodological quality of all included studies were assessed according to the National Institutes of Health (NIHs) quality assessment tool for observational cohort studies. [26] The tool comprises 14 criteria stated in the form of a question that can be answered as 'yes', 'no', or 'not applicable'/'not reported'/'cannot determine'. It contains questions that address the sampling, exposure and outcome measurement, the clarity in stating different components of the study, control of confounders, and validity of the study. After carefully evaluating each study against these criteria, each study was classified as being either of 'good,' 'fair', or 'poor' quality. 'Good' quality was assigned to those studies that fulfilled $85 \%$ or more of the criteria. If $30 \%$ of the criteria or under was not fulfilled, the study was considered to be of poor quality. 


\section{Data extraction}

Relevant information such as study design, study setting, follow-up period, sample size, baseline characteristics of study subjects, fever clearance, parasite clearance, treatment failure, and cure rates were extracted from each article using the well-prepared and piloted data extraction format in the form of table.

\section{Data analysis}

Meta-analysis was performed using Comprehensive Meta-Analysis software version 2.2.064 [27]. Continuous data were presented as mean \pm standard deviation. The proportion of the cure rate was calculated based on per protocol and intention-to-treat analysis. The cure rate and $95 \%$ confidence intervals were calculated using the DerSimonian-Laird statistical method assuming a random effect model. Since four of the studies did not report the polymerase chain reaction (PCR) corrected cure rate only six studies were included in the PCR corrected cure rate analysis. But all of the 10 studies were included in the PCR uncorrected cure rate analysis.

\section{Results}

\section{Literature search results}

A total of 235 articles were initially retrieved. After excluding duplicates, the titles of 212 articles were assessed and 197 were found to be irrelevant. Abstracts of the remaining 15 articles were checked to determine if they fulfilled the inclusion criteria. Of those, five were rejected: two were done on non-human subjects, one was published before 2010, and the full text was not available for the other two. In the end, 10 articles were found to be suitable to be included in this study. Figure 1 shows the entire article selection process.

\section{Study characteristics}

All 10 studies included in this review were prospective single-arm cohort studies that determined the efficacy of $\mathrm{AL}$ in the treatment of uncomplicated $P$. falciparum malaria in Ethiopia.

The studies were conducted in different malarious parts of the country (north, south, east, and central Ethiopia). The WHO guide for surveillance of antimalarial drug efficacy was used in all of the studies to select subjects and to conduct the study.

In the majority $(8 / 10,80 \%)$ of the studies, subjects were followed for 28 days, while in the remaining $(2 / 10,20 \%)$ studies, the follow-up period was 42 days. In each study, anywhere from 66 to 384 patients with $P$. falciparum mono-infection were included. Most $(7 / 10,70 \%)$ of the studies followed patients who were older than six months. One study excluded patients who were below one year of age and another excluded children under five years of age. Details of each study are summarized in Table 1.

\section{Methodological quality of included studies}

Each article was evaluated against 14 criteria using the NIHs quality assessment tool for observational cohort studies [26]. Fortunately all of the 10 studies included in this review were found to be of good quality.

\section{Baseline characteristics of the study subjects}

The 10 studies included a total of 1179 participants from 14 study sites. The mean age of study participants was 15.8 years. At recruitment, the average parasite count per patient was $12,981 / \mu \mathrm{l}$ of blood and gametocytes were found in $7.7 \%$ of patients. Table 2 shows the mean and standard deviations of baseline characteristics of patients included in the 10 studies.

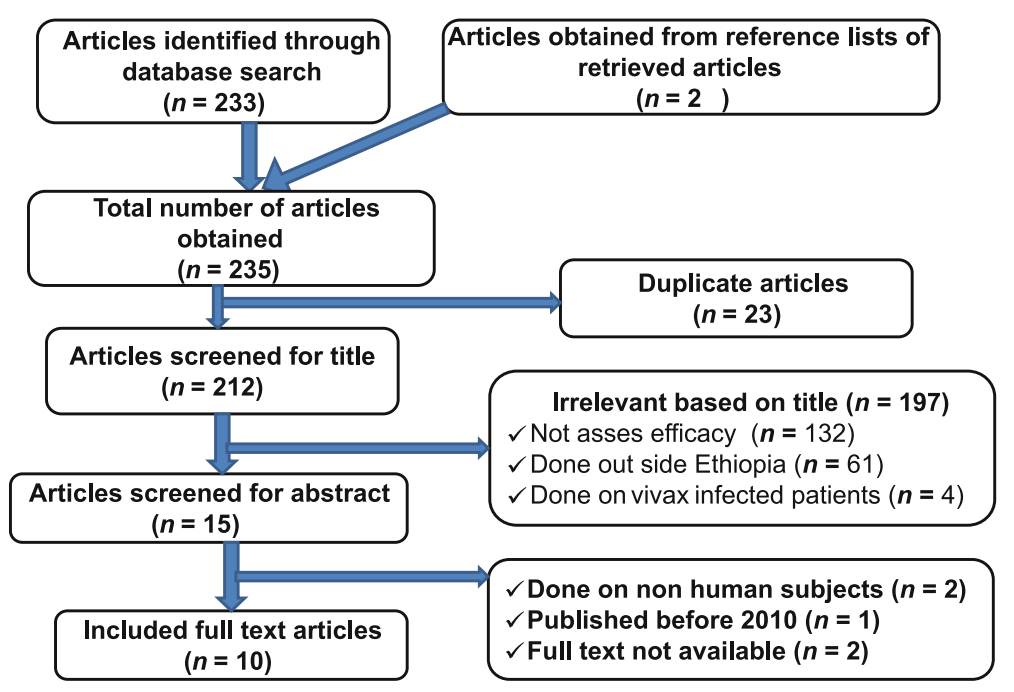

Fig. 1 Article selection process 
Table 1 Description of individual study characteristics

\begin{tabular}{|c|c|c|c|c|c|c|c|}
\hline \multirow{2}{*}{$\begin{array}{l}\text { sr. } \\
\text { no }\end{array}$} & \multirow{2}{*}{$\begin{array}{l}\text { Author (year } \\
\text { of } \\
\text { publication) }\end{array}$} & \multirow[t]{2}{*}{ Study design } & \multirow[t]{2}{*}{ Study setting } & \multirow[t]{2}{*}{ Study period } & \multirow{2}{*}{$\begin{array}{l}\text { Follow } \\
\text { up }\end{array}$} & \multicolumn{2}{|l|}{ Subjects } \\
\hline & & & & & & $\begin{array}{l}\text { Sample } \\
\text { size }\end{array}$ & $\begin{array}{l}\text { Inclusion } \\
\text { for age }\end{array}$ \\
\hline 1 & $\begin{array}{l}\text { Mekonnen SK. } \\
\text { et al. (2015) } \\
{[28]}\end{array}$ & $\begin{array}{l}\text { single arm, open } \\
\text { label Prospective } \\
\text { cohort study }\end{array}$ & $\begin{array}{l}\text { Omo Nada health center in } \\
\text { southwestern Ethiopia }\end{array}$ & Augest-december 2011 & 28 days & 89 & $\begin{array}{l}> \\
6 \text { months } \\
\text { old }\end{array}$ \\
\hline 2 & $\begin{array}{l}\text { Ebstie YA. } \\
\text { et al. (2015) } \\
{[29]}\end{array}$ & $\begin{array}{l}\text { single arm, open } \\
\text { label Prospective } \\
\text { cohort study }\end{array}$ & Bahir Dar district, Northwest Ethiopia & March and July 2012 & 28 day & 134 & $\begin{array}{l}>5 \text { years } \\
\text { old }\end{array}$ \\
\hline 3 & $\begin{array}{l}\text { Eshetu T. } \\
\text { et al. (2012) } \\
\text { [30] }\end{array}$ & $\begin{array}{l}\text { single arm, open } \\
\text { label Prospective } \\
\text { cohort study }\end{array}$ & $\begin{array}{l}\text { Agaro Health Centre, Jimma Health } \\
\text { Centre, Serbo Health Centre, and } \\
\text { Asendabo Health Centre }\end{array}$ & $\begin{array}{l}\text { November } 2008 \text { and January } \\
2009 \text { and between August and } \\
\text { December } 2009 \text {. }\end{array}$ & 42 day & 348 & $>1$ year \\
\hline 4 & $\begin{array}{l}\text { Mulu A. et al. } \\
\text { (2015) [31] }\end{array}$ & $\begin{array}{l}\text { single arm, open } \\
\text { label Prospective } \\
\text { cohort study }\end{array}$ & $\begin{array}{l}\text { Kemisie Health Center, Northeast } \\
\text { Ethiopia }\end{array}$ & September, 2012 to May, 2013 & 28 days & 66 & $\begin{array}{l}> \\
6 \text { months } \\
\text { old }\end{array}$ \\
\hline 5 & $\begin{array}{l}\text { Hwang J. } \\
\text { et al. (2011) } \\
\text { [32] }\end{array}$ & $\begin{array}{l}\text { single arm, open } \\
\text { label Prospective } \\
\text { cohort study }\end{array}$ & $\begin{array}{l}\text { Bishoftu Malaria Clinic and Bulbula } \\
\text { Health Center, Oromia Regional State }\end{array}$ & October and November 2009 & 42 days & 119 & $\begin{array}{l}> \\
6 \text { months } \\
\text { old }\end{array}$ \\
\hline 6 & $\begin{array}{l}\text { Nega D et al. } \\
\text { (2016) [33] }\end{array}$ & $\begin{array}{l}\text { single arm, open } \\
\text { label Prospective } \\
\text { cohort study }\end{array}$ & $\begin{array}{l}\text { Metehara Health Centre, Eastern } \\
\text { Ethiopia }\end{array}$ & October 2014 to January 2015 & 28 days & 91 & $\begin{array}{l}\geq \\
6 \text { months } \\
\text { old }\end{array}$ \\
\hline 7 & $\begin{array}{l}\text { Getnet G. } \\
\text { et al. (2015) } \\
\text { [34] }\end{array}$ & $\begin{array}{l}\text { single arm, open } \\
\text { label Prospective } \\
\text { cohort study }\end{array}$ & Enfranze Health Centrer, NW ethiopia & January and May 2013 & 28-day & 80 & $\begin{array}{l}> \\
6 \text { months } \\
\text { old }\end{array}$ \\
\hline 8 & $\begin{array}{l}\text { Assefa A. } \\
\text { et al. }(2010)^{17}\end{array}$ & $\begin{array}{l}\text { single arm, open } \\
\text { label Prospective } \\
\text { cohort study }\end{array}$ & $\begin{array}{l}\text { Serbo Health Center, Kersa District, SW } \\
\text { Ethiopia. }\end{array}$ & $\begin{array}{l}\text { November } 2007 \text { and January } \\
2008\end{array}$ & 28 day & 90 & NR \\
\hline 9 & $\begin{array}{l}\text { Kinfu G. et al. } \\
\text { (2012) [35] }\end{array}$ & $\begin{array}{l}\text { single arm, open } \\
\text { label Prospective } \\
\text { cohort study }\end{array}$ & $\begin{array}{l}\text { Tumuga health center Alamata district, } \\
\text { Tigrai regional state, North Ethiopia }\end{array}$ & August-November 2009. & 28 days & 71 & $\begin{array}{l}> \\
6 \text { months } \\
\text { old }\end{array}$ \\
\hline 10 & $\begin{array}{l}\text { Wudneh F. } \\
\text { et al. (2016) } \\
{[36]}\end{array}$ & $\begin{array}{l}\text { one-arm } \\
\text { prospective open } \\
\text { label trial }\end{array}$ & $\begin{array}{l}\text { Gendewuha (Metema) Health Center, } \\
\text { NW ethiopia }\end{array}$ & October 2014 to January 2015 & 28-day & 91 & $\begin{array}{l}> \\
6 \text { months } \\
\text { old }\end{array}$ \\
\hline
\end{tabular}

\section{Fever and parasite clearance rate}

Fever and parasite clearance was rapid. On the third day of treatment, $96.7 \%$ and $98.5 \%$ of study subjects become fever-free and parasite-free, respectively. There was also a significant decrease in gametocyte carriage from $7.7 \%$ at baseline to $0.4 \%$ on the 28 th day of treatment. Table 3 shows the overall progress of fever and parasite clearance in the first three days of AL treatment.

Table 2 Mean baseline characteristics of patients with uncomplicated Falciparum malaria

\begin{tabular}{lll}
\hline Characteristics & Mean value & Standard deviation \\
\hline Age & 15.8 years & 3.4 \\
Weight & $37.3 \mathrm{~kg}$ & 6.3 \\
Temperature & $38.2^{\circ} \mathrm{C}$ & 0.35 \\
Hemoglobin & $12.2 \mathrm{mg} / \mathrm{dl}$ & 0.89 \\
Parasite load & 12,981 Parasites $/ \mu \mathrm{l}$ & 5261 \\
Patients with Gametocyte & $7.7 \%$ & 4.3 \\
\hline
\end{tabular}

\section{Treatment outcome}

Of the 1179 subjects included in the 10 studies reviewed, only $27(2.29 \%)$ showed treatment failure. As shown in Table 4, the common type of treatment failure was late parasitological failure, which accounted for $55 \%$ of all treatment failures. Based on the per protocol analysis, the cure rate using AL was 98.2\% (PCR corrected) and 97.01\% (PCR uncorrected). This shows that the reinfection rate within 28 days was $1.1 \%$ and the recrudescence rate was $1.9 \%$. Reinfection is the development of malarial signs and symptoms due to a new strain, while recrudescence indicates that the infection has recurred from persistent blood stages of the malaria parasite (Additional file 2).

Heterogeneity between the studies was minimal $\left(\mathrm{I}^{\wedge}{ }^{2}=38.8\right)$. As shown in the forest plots provided in Figs. 2

Table 3 Fever and parasite clearance rate in the first 3 days of treatment

\begin{tabular}{llll}
\hline Parameter & Day 1 & Day 2 & Day 3 \\
\hline Fever clearance & $76.8 \%$ & $95.6 \%$ & $96.7 \%$ \\
Parasite clearance & $68.1 \%$ & $93.9 \%$ & $98.5 \%$ \\
\hline
\end{tabular}

Treatment outcome 
Table 4 Treatment outcome

\begin{tabular}{|c|c|c|c|}
\hline \multicolumn{3}{|c|}{ Outcome $^{a}$} & \multirow{2}{*}{$\frac{n(\%)}{3(0.25 \%)}$} \\
\hline \multirow{3}{*}{\multicolumn{2}{|c|}{ Treatment failure }} & ETF $n(\%)$ & \\
\hline & & LPF $n(\%)$ & $15(1.27 \%)$ \\
\hline & & LCF $n(\%)$ & $9(0.76 \%)$ \\
\hline \multicolumn{2}{|c|}{ Adequate response } & ACPR & $95.5 \%$ \\
\hline \multirow[t]{4}{*}{ Cure rate } & Per protocol analysis & PCR unadjusted (\%) & $97.2 \%$ \\
\hline & & PCR adjusted (\%) & $98.2 \%$ \\
\hline & Intension to treat analysis & PCR unadjusted (\%) & $92.04 \%$ \\
\hline & & PCR adjusted (\%) & $92.98 \%$ \\
\hline
\end{tabular}

athis is reported based on 28 days follow up outcome for all the studies

and 3, the 95\% confidence interval was overlapping and there was no any outlier study i.e. there is no data value that differ greatly from the majority of data sets (cure rate). The PCR corrected and PCR uncorrected overall cure rates (summary effect) of AL were 0.982 and 0.972 , respectively.

\section{Discussion}

AL has been the first-line drug used in Ethiopia for the treatment of uncomplicated falciparum malaria since 2004 after the development of resistance for older antimalarials such as chloroquine and sulphadoxinepyrimethamine [37]. Since its introduction, no significant AL-resistant $P$. falciparum cases have been reported in the country $[17,31,32,38]$. The adequate clinical and parasitological responses observed in this analysis similarly show a high efficacy of AL against uncomplicated P. falciparum malaria in Ethiopia.

The mean temperature of patients on the day of enrolment was $38.2 \pm 0.35{ }^{\circ} \mathrm{C}$. Closer mean temperature at day zero was reported in similar studies conducted in Sudan $\left(38.5 \pm 0.6{ }^{\circ} \mathrm{C}\right)[39]$ and Zambia $\left(38.7{ }^{\circ} \mathrm{C}\right)$ [40]. The fever clearance rate of AL was rapid. Fever is one of the common manifestations of malaria that frequently causes discomfort. Thus, it was encouraging that more than $95 \%$ of patients treated with AL become fever-free within the first two to three days. Administration of an antipyretic (paracetamol) for febrile patients (body temperature above $38{ }^{\circ} \mathrm{C}$ ) is common practice. The use of $\mathrm{AL}$ for treatment of uncomplicated $P$. falciparum malaria reduces the number of patients who require paracetamol during the follow-up period, which means that the number of drugs taken by patients and thus the risks associated with them is reduced. Other studies also confirm the rapid fever clearance capacity of $\mathrm{AL}$ [41-43]. This inherent nature of AL of being able to rapidly reduce or resolve clinical symptoms makes it attractive for patients.

From the 1179 patients included in the 10 studies, 1161 (98.5\%) had parasitic clearance within the first three days of treatment with AL. This rate of parasite clearance was consistent with other reports [44-47]. In

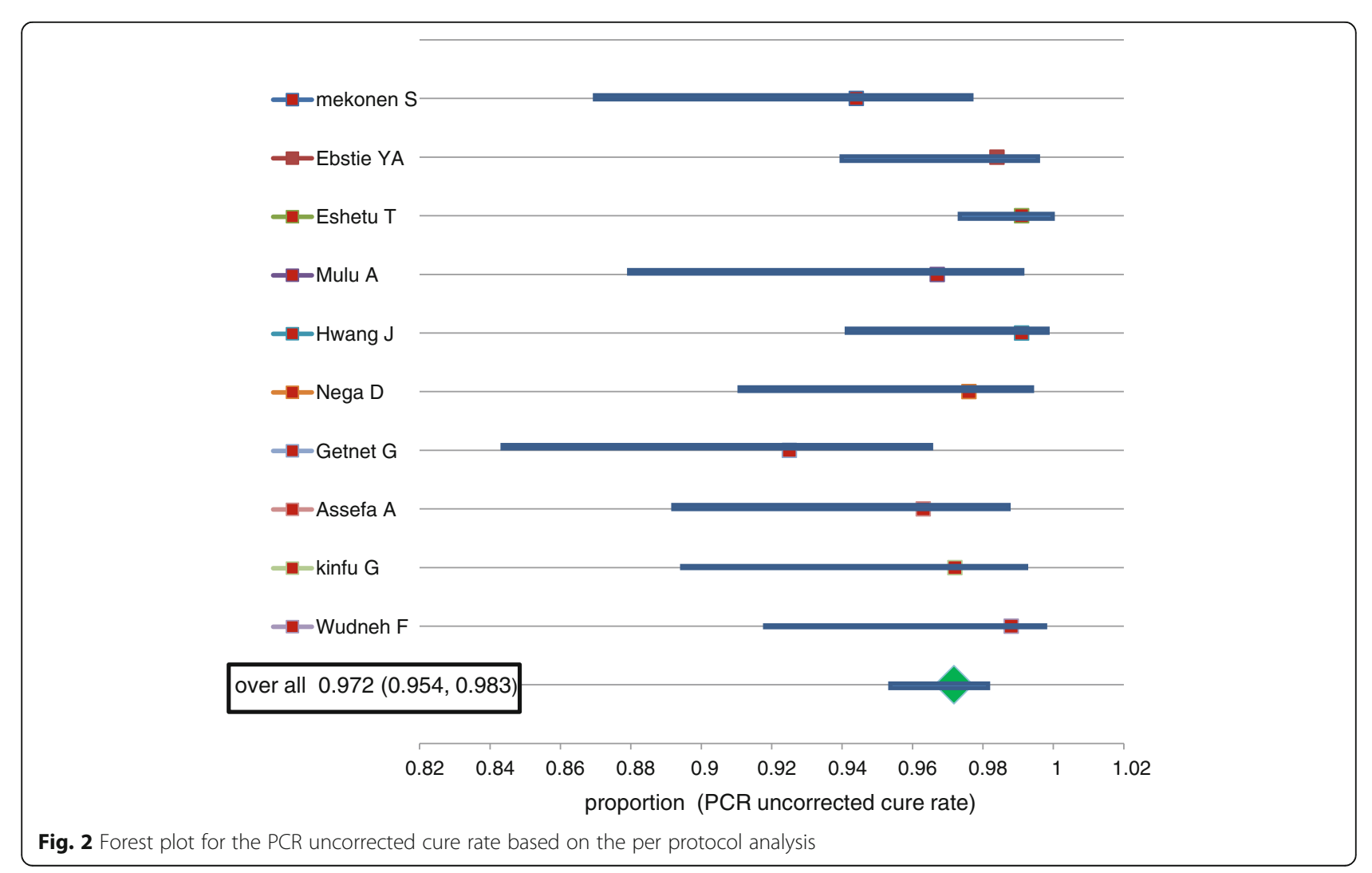




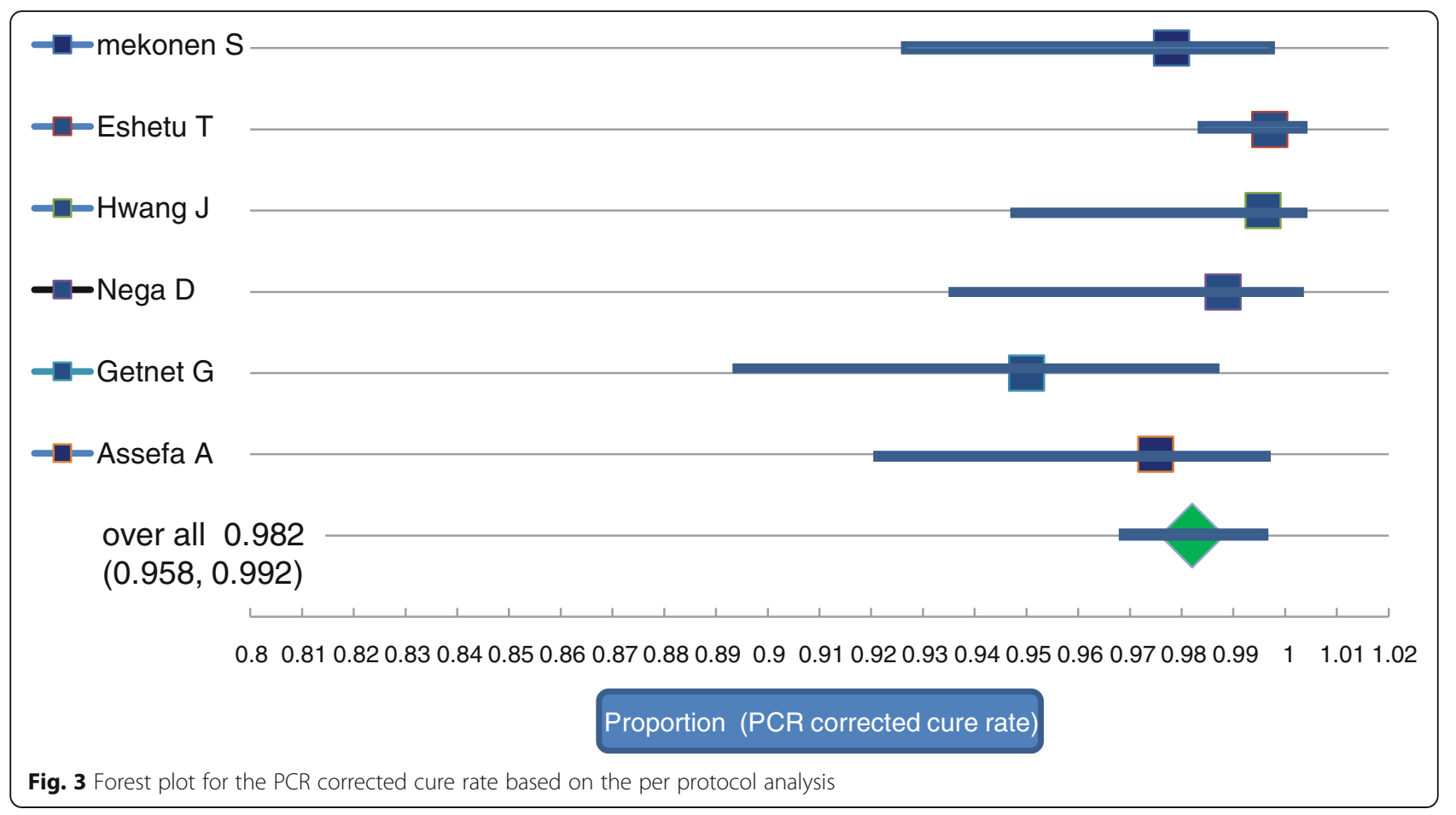

addition to the rapid parasite clearance, there was also a significant decrease in gametocyte carriage, from $7.7 \%$ at baseline to $0.4 \%$ on the 28 th day of treatment. As confirmed by other studies, artemisinin-based combination therapy is known for its rapid parasite clearance rate and for reducing gametocyte carriage. The low gametocyte carriage after treatment reduces transmission of gametocytes to mosquitoes. Therefore, AL would not only reduce the problem of resistant malaria but also lessen the chances that an infected person might transmit the infection to mosquitoes and to other members of the community [48, 49].Previous studies have reported that artemisinin derivatives are gametocidal $[50,51]$.The very small proportion of patients with gametocytes at day 28 , as found from reviewing 10 studies in this report, supports the results obtained by Targett et al., who reported that an artemisinin derivative has an effect on the sexual stage of the parasite and that specifically AL can decrease gametocytes by $6-8$ fold as compared to chloroquine and sulphadoxine-pyrimethamine [51].

In contrast to the finding of the current review, a slower parasite clearance rate and increased third day parasitemia was reported in studies conducted on the Thai-Cambodian border [23, 24].The higher third day parasitic clearance rate (1.5\% parasite positivity) reported in the present study may indicate less probability of AL resistance, as Stepniewska et al. explained that resistance is unlikely if the proportion of day three parasite positive smear is less than $3 \%$ [52].
The PCR corrected cure rate of AL in the current review was found to be $98.2 \%$. This reveals that $\mathrm{AL}$ is highly effective in the treatment of uncomplicated $P$. falciparum malaria. Similar findings were reported by other studies conducted in different parts of the world [16, 53-55]. Studies conducted in East African countries also report a high efficacy of AL [56-59]. A meta-analysis published in 2009 that addressed 32 randomized studies on efficacy of AL reported a 28-day PCR corrected parasitological cure rate of 97\% [60]. A community-based study conducted in three African countries (including Ethiopia) also reported that AL was effective in reducing the risk of malaria-specific mortality by $37 \%$ [25].

The WHO recommends that for an antimalarial drug to be selected as a first-line treatment agent, it should have a clinical and parasitological cure rate of $90 \%$ or higher [15]. The result of the current review is in agreement with the WHO requirement to support the firstline use of $\mathrm{AL}$ in the treatment of uncomplicated $P$. falciparum malaria. Therefore, in Ethiopia AL can still be used as a first-line agent in the treatment of uncomplicated P. falciparum malaria. This will not, however, guarantee the avoidance of subsequent timely monitoring for its efficacy. The WHO has said that the efficacy of first-line medicines must be cheeked at least every two years [15].

The follow-up period in most of the studies reviewed was 28 days. Two of the studies followed patients for 42 days and one of them reported that the rate of recrudescence was higher at day 42 than at day 28 (PCR 
corrected cure rate of $94.3 \%$ at day 42 and $99.7 \%$ at day 28 using per protocol analysis) [30]. This indicates that treatment failure may occur even after longer periods. Therefore, studies that measure the efficacy of AL beyond one month (28 days) are recommended.

In all of the 10 studies reviewed, drug levels were not tested, therefore it is difficult to attribute treatment failure to the drug's ineffectiveness or development of resistance, as it may be due to insufficient drug levels. It is thus better if future studies conducted on AL efficacy measure the serum drug levels and correlate these with the outcome. Sensitivity of PCR genotyping may have also affected the results of this review, as similar strains, defined as recrudescence, could be new infections, especially in low to moderate transmission areas with a limited diversity of strains [61].

Even though the morning doses of AL were taken in front of investigators in most of the studies, the night time intake of the drug was not directly controlled. Therefore, it was difficult to determine whether some of the treatment failure cases reported were due to low adherence. There are also many other factors that may influence the treatment outcome. Further studies that identify risk factors for treatment failure should be conducted. Studies that describe in detail the characteristics of patients with recrudescence are also very important. Molecular surveillance may also play an important role in detecting genetic markers associated with AL resistance in the local P. falciparum population.

\section{Conclusions}

AL is highly efficacious in Ethiopia for the treatment of uncomplicated $P$. falciparum malaria even after a number of years of its widespread use in the country. There should, however, be careful periodic monitoring of the efficacy of this drug, as treatment failure may occur due to resistance, sub-therapeutic levels that may occur due to non-adherence, or inadequate absorption.

\section{Additional files}

Additional file 1: Multilingual abstracts in the five official working languages of the United Nations. (PDF $799 \mathrm{~kb}$ )

Additional file 2: Treatment outcome from individual study. (DOCX $18 \mathrm{~kb}$ )

\section{Abbreviations}

AL: artemether-lumefantrine; NIH: National Institute of Health; PCR: polymerase chain reaction; WHO: World Health Organization

\section{Acknowledgments}

The author would like to express his thanks to the University of Gondar for giving him an internet access.

Author contributions

Not applicable (because this is a sole author paper).

\section{Funding}

This research did not receive any specific grant from funding agencies in the public, commercial, or not-for-profit sectors.

\section{Availability of data and materials}

Not applicable.

Ethics approval and consent to participate

Not applicable (because this is a review).

\section{Consent for publication}

Not applicable (because this is a sole author paper).

\section{Competing interests}

The author declares that he has no competing interests.

Received: 3 March 2017 Accepted: 26 October 2017

Published online: 15 November 2017

References

1. WHO. World Malaria Report. December2015.http://www.who.int/malaria/ publications/world-malaria-report-2015/report/en/. Accessed 8 April. 2015: 2017.

2. Barofsky J, Chase C, Anekwe T and Farzadfar F, 2011. The economic effects of malaria eradication:Evidence from an intervention in Uganda. PGDA Working Papers, Program on the Global Demography of Aging. http://www. hsph.harvard.edu/pgda/WorkingPapers/2011/PGDA_WP_70.pdf. Accessed 12 March, 2017.

3. President's malaria initiative. Malaria operational plan FY 2017. President's malaria initiative, Ethiopia. https://reliefweb.int/report/ethiopia/president-smalaria-initiative-ethiopia-malaria-operational-plan-fy-2017 Accessed 23 April, 2017.

4. Federal Ministry of Health. National five-year strategic plan for malaria prevention and control in Ethiopia 2006-2010. Federal Ministry of Health, Addis Ababa. 2006. http://www.cdbph.org/documents/who_evipnet documents_guideline_Ethiopia\%20National_Five_Year_Strategic_Plan.pdf. Accessed 18 Feb, 2017.

5. Adugna A. Malaria in Ethiopia. Available at http://www. ethiodemographyandhealth.org/MedVectoredDiseasesMalaria.pdf. Accessed 10 Feb 2017.

6. Mitikie G, Addissie M, Admassu M, Tadesse A, Feleke A, Alebachew H. Malaria for the Ethiopian health center team. Gondar College of Medicine and Health Sciences in Collaboration with the Ethiopia public health training initiative, the Carter Center, the Ethiopia Ministry of Health and the Ethiopia ministry of. Education. 2005:17. https://www.cartercenter.org/ resources/pdfs/health/ephti/library/modules/finalmodulemalariaupdated.pdf. Accessed 10 Feb 2017

7. Federal Ministry of Health of Ethiopia. Malaria diagnosis and treatment a guideline for health workers in Ethiopia. Federal Ministry of Health, Addis Ababa. 2004. http://www.who.int/countries/eth/publications/malaria treatment.pdf. Accessed 15 March 2017.

8. Alene GD, Bennett $\mathrm{S}$. Chloroquine resistance of Plasmodium falciparum malaria in Ethiopia and Eritrea. Tropical Med Int Health. 1996;1:810-5.

9. Kebede F, Taffa N, Tedla T. An in-vivo study of Falciparum malaria sensitivity to chloroquine in unstable malaria endemic area of central Ethiopia. Ethiop Med J. 1999;37:97-109.

10. Tulu AN, Webber RH, Schellenberg JA, Bradley DJ. Failure of chloroquine treatment for malaria in the highlands of Ethiopia. Trans R Soc Trop Med Hyg. 1996:90:556-7.

11. Jima D, Tesfaye G, Medhin A, Kebede A, Argaw D, Babaniyi O. Efficacy of sulfadoxine-pyrimethamine for the treatment of uncomplicated Falciparum malaria in Ethiopia. East African Med J. 2005;82:391-5.

12. Guthmann JP, Bonnet M, Ahoua L, Dantoine F, Balkan S, van Herp M, et al. Death rates from malaria epidemics, Burundi and Ethiopia. Emerg Infect Dis. 2007;13:140-3.

13. Kassa M, Sileshi M, Mohammed H, Taye G, Asfaw M. Development of resistance by Plasmodium falciparum to sulfadoxine/pyrimethamine in Amhara region, north western Ethiopia. Ethiop Med J. 2005:43:181-7.

14. WHO. World malaria report. Geneva: World Health Organization; 2009. whalibdoc.who.int/publications/2009/9789241563901_eng.Pdf. Accessed 9 Jan, 2017. 
15. WHO. Guidelines for the treatment of malaria 2nd edition. Geneva: World Health Organization; 2010. http://whqlibdoc.who.int/publications/2010/ 9789241547925_eng.pdf. Accessed 6 April, 2017.

16. Fanello Cl, Karema C, Van Doren W, Van Overmeir C, Ngamije D, D'Alessandro UA. Randomised trial to assess the safety and efficacy of artemether-lumefantrine (Coartem ${ }^{\circledast}$ ) for the treatment of uncomplicated Plasmodium falciparum malaria in Rwanda. Trans R Soc Trop Med Hyg. 2007; 101:344-50.

17. Assefa A, Kassa M, Tadese G, Mohamed H, Animut A, Mengesha T. Therapeutic efficacy of artemether/lumefantrine (Coartem ${ }^{\circledast}$ ) against Plasmodium falciparum in Kersa, south West Ethiopia. Parasit Vectors. 2010;3:1-4.

18. Van Vugt M, Looareesuwan S, Wilairatana P, McGready R, Villegas $L$, Gathmann I, et al. Artemether-lumefantrine for the treatment of multidrugresistant Falciparum malaria. Trans R Soc Trop Med Hyg. 2000;94:545-8.

19. Lefèvre G, Looareesuwan S, Treeprasertsuk S, Krudsood S, Silachamroon U, Gathmann I, et al. A clinical and pharmacokinetic trial of six doses of artemether-lumefantrine for multidrug-resistant Plasmodium falciparum malaria in Thailand. Am J Trop Med Hyg. 2001;64:247-56.

20. Sisowath C, Strömberg J, Mårtensson A, Msellem M, Obondo C, Björkman A et al. Vivo selection of Plasmodium falciparum pfmdr1 $86 \mathrm{~N}$ coding alleles by Artemether-lumefantrine (Coartem ${ }^{\circledast}$ ). J Infect Dis. 2005;191:1014-27.

21. Mizuno $Y$, Kato $Y$, Kudo K, Kano S. First case of treatment failure of artemether-lumefantrine in a Japanese traveller with imported Falciparum malaria. Jpn J Infect Dis. 2009;62:139-41.

22. Borrmann S, Sasi P, Mwai L, Bashraheil M, Abdallah A, Muriithi S, et al. Declining responsiveness of Plasmodium falciparum infections to artemisinin-based combination treatments on the Kenyan coast. PLoS One. 2011;6:e26005

23. Dondorp AM, Nosten F, Yi P, Das D, Phyo AP, Tarning J, et al. Artemisinin resistance in Plasmodium falciparum malaria. N Engl J Med. 2009;361(5):455-67.

24. Noedl H, Se Y, Schaecher K, Smith BL, Socheat D, Fukuda MM, et al. Evidence of artemisinin-resistant malaria in western Cambodia. N Engl J Med. 2008;359(24):2619-20.

25. Barnes Kl, Chanda P, Ab Barnabas G. Impact of the large-scale deployment of artemether/lumefantrine on the malaria disease burden in Africa: case studies of South Africa. Zambia and Ethiopia Malar J. 2009;8(Suppl 1):S8.

26. National institute of health. Quality Assessment Tool for Observational Cohort and Cross-Sectional Studies. available at https://www.nhlbi.nih.gov/ about/site-index.accessed 9 Feb, 2017.

27. Borenstein $M$, Hedges L, Higgins J, Rothstein H. Comprehensive metaanalysis version 2.2.064. Biostat: Englewood; 2011. https://doi.org/10.1002/ 9780470114735.hawley03918.

28. Mekonnen SK, Medhin G, Berhe N, Clouse RM, Aseffa A. Efficacy of artemether-lumefantrine therapy for the treatment of uncomplicated Plasmodium falciparum malaria in southwestern Ethiopia. Malar J. 2015;14:317.

29. Ebstie YA, Zeynudin A, Belachew T, Desalegn Z, Suleman S. Assessment of therapeutic efficacy and safetyof artemether-lumefantrine (Coartem ${ }^{\oplus}$ ) in thetreatment of uncomplicated Plasmodium falciparum malaria patients in Bahir Dardistrict. Northwest Ethiopia: an observationalcohort study Malar J. 2015;14:236

30. Eshetu T, Abdo N, Bedru KH, Fekadu S, Wieser A, Pritsch M, et al. Open-label trial with artemetherlumefantrine against uncomplicated Plasmodium falciparum malaria three years after its broad introduction in Jimma zone, Ethiopia. Malar J. 2012;11:240.

31. Mulu A, Geresu B, Beyene Y, Ademe M. Efficacy of Artemether-lumefantrine for the treatment of uncomplicated Plasmodium falciparum malaria in Northeast Ethiopia. Int J Basic ClinPharmacol. 2015:4(3):492-6.

32. Hwang J, Alemayehu BH, Hoos D, Malone JL, Kachur SP, Filler S, et al. In vivo efficacy of Artemether-lumefantrine against uncomplicated Plasmodium falciparum malaria in Central Ethiopia. Malar J. 2011;10(1):209.

33. Nega D, Assefa A, Mohamed H. SolomonH, Woyessa a, Assefa Y, et al. TherapeuticEfficacy of Artemether-Lumefantrine (Coartem) inTreating uncomplicated $P$. falciparum malaria inMetehara, eastern Ethiopia: regulatory clinical study. PLoS One. 2016;11(4):e0154618. https://doi.org/10. 1371/journal.pone.0154618.

34. Getnet G, Fola AA, Alemu A, Getie S, Fuehrer HP, Noedl H. Therapeutic efficacy of artemether-lumefantrine for the treatmentof uncomplicated Plasmodium falciparummalaria in Enfranze, north-west Ethiopia. Malar J. $2015 ; 14: 258$
35. Kinfu G, Gebre-Selassie S, Fikrie N. Therapeutic efficacy of Artemetherlumefantrine for the treatment of uncomplicated Plasmodium falciparum malaria in northern Ethiopia. Malaria research and treatment. 2012; https:// doi.org/10.1155/2012/548710

36. Wudneh F, Assefa A, Nega D, Mohammed H, Solomon H, Kebede T, et al. Open-label trial on efficacy of artemether/lumefantrine against the uncomplicated Plasmodium falciparum malaria in Metema district, northwestern Ethiopia. Ther Clin Risk Manag. 2016;12:1293-300.

37. Federal Democratic Republic of Ethiopia, Ministry of Health: Malaria diagnosis and treatment guidelines for health workers in Ethiopia. 2nd edition. Addis Ababa Minist heal, 2004. www.who.int/countries/eth/ publications/malaria_treatment.pdf. Accessed 15 March 2017.

38. Kefyalew T, Animut A, Tamene T, Jima D, Hailemariam A, Legesse M, et al. Efficacy of six-dose regimen of Artemether-Lumefantrine for the treatment of uncomplicated Falciparum malaria, three years after its introduction into Ethiopia. Parasite. 2009;16:129-34. 19585891

39. Salah MT, Faroung M, Magzoub MM, Adam I. Efficacy of artemetherlumefantrine (Coartem) suspension in the treatment of uncomplicated Plasmodium falciparum malaria among children under 5 years in eastern Sudan. Trop J Pharm Res. 2006;5(1):551-5.

40. Chanda P, Hawela M, Kango M, Sipilanyambe N. Assessment of the therapeutic efficacy of a paediatric formulation of artemether-lumefantrine (coartesiane) for the treatment of uncomplicated Plasmodium falciparum in children in Zambia. Malar J. 2006; 5(75).

41. Fogg C, Bajunirwe F, Piola P, Biraro S, Checchi F, Kiguli J, et al. Adherence to a six-dose regimen of artemether-lumefantrine for treatment of uncomplicated Plasmodium falciparummalaria in Uganda. Am J Trop Med Hyg. 2004;71:525-30.

42. Internatioanal Artemisinin study group. Artesunate combination for treatment of malaria: meta-analysis. Lancet. 2004;363:9-17.

43. Piola P, Fogg C, Bajunirwe F, Biraro S, Grandesso F, Ruzagira E, et al. Supervised versus unsupervised intake of six-dose artemether-lumefantrine for treatment of acute, uncomplicated Plasmodium falciparum malaria in Mbarara, Uganda: a randomised trial. Lancet. 2005;365:1467-73.

44. Dorsey G, Staedke S, Clark TD, Njama-Meya D, Nzarubara B, MaitekiSebuguzi

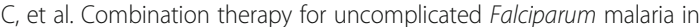
Ugandan children: a randomized trial. JAMA. 2007;297:2210-9.

45. Arinaitwe E, Sandison TG, Wanzira H, Kakuru A, Homsy J, Kalamya J, et al. Artemether-lumefantrine versus dihydroartemisinin-piperaquine for Falciparum malaria: a longitudinal, randomized trial in young Ugandan children. Clin Infect Dis. 2009;49:1629-37.

46. Sagara I, Rulisa S, Mbacham W, Adam I, Sissoko K, Maiga H, et al. Efficacy and safety of a fixed dose Artesunate-sulphamethoxypyrazinepyrimethamine compared to Artemether-lumefantrine for the treatment of uncomplicated Falciparum malaria across Africa: a randomized multicentre trial. Malar J. 2009:8:63

47. Valecha N, Srivastava P, Mohanty SS, Mittra P, Sharma KS, Tyagi KP, et al. Therapeutic efficacy of artemether-lumefantrine in uncomplicated Falciparum malaria in India. Malar J. 2009; 8:107. doi: https://doi.org/10.1186/ 14752875-8-107 PMID: 19454000

48. Adjuik M, Babiker A, Garner P, Olliaro P, Taylor W, White N, et al. International Artemisinin study group, Artesunate combinations for treatment of malaria: meta-analysis. Lancet. 2004;363:9-17. 14723987

49. Price RN, Nosten F, Luxemburger C, Paiphun L, Chongsuphajaisiddhi T, White $\mathrm{NJ}$, et al. Effects of artemisinin derivatives on malaria transmissibility. Lancet. 1996;347:1654-8. 8642959

50. Novartis pharma AG: International package leaflet. Basel, Switzerland 2005. https://www1.ndmctsgh.edu.tw/pharm/pic/medinsert/005ZOM01E.pdf. Accessed 15 Jan, 2017

51. Targett G, Drakeley C, Jawara M, Seidlein L, Coleman R, Deen J, et al. Artesunate reduces but does not prevent post treatment transmission of Plasmodium falciparum to Anopheles gambiae. J Inf Dis. 2001;183:1254-9.

52. Stepniewska K, Ashley E, Lee SJ, Anstey N, Barnes Kl, Binh TQ, et al. Vivo parasitological measures of artemisinin susceptibility. J Infect Dis. 2010;201:570-9.

53. Bukirwa H, Yeka A, Kamya MR, Talisuna A, Banek K, Bakyaita N, et al. Artemisinin combination therapies for treatment of uncomplicated malaria in Uganda. PLoS Clin Trials. 2006;e7:1.

54. Faye B, Ndiaye JL, Tine R, Sylla K, Gueye A, Lo AC, et al. A randomized trial of Artesunate mefloquine versus Artemether lumefantrine for the treatment of uncomplicated Plasmodium falciparum malaria in Senegalese children. Am J Trop Med Hyg. 2010;82:140-4. 
55. Faye B, Offianan AT, Ndiaye JL, Tine RC, Toure W, Djoman K, et al. Efficacy and tolerability of Artesunate amodiaquine (Camoquin plus) versus Artemether-lumefantrine (Coartem) against uncomplicated Plasmodium falciparum malaria: multisite trial in Senegal and Ivory Coast. Tropical Med Int Health. 2010;15:608-13.

56. Elamin SB, Awad Al, Eltayeb IB, Elmardi KA, Hassan AH, Mohamed AO, et al. Descriptive study on the efficacy of artemether-lumefantrine in the treatment of uncomplicated Plasmodium falciparum malaria in Sudan. Eur J ClinPharmacol. 2010;66:231-7.

57. Joseph D, Kabanywanyi AM, Hulser R, Premji Z, Minzi OM, Mugittu K. Exploration of in vivo efficacy of artemether-lumefantrine against uncomplicated Plasmodium falciparum malaria in under fives in Tabora region. Tanzania Malar J. 2013;12:60.

58. Yeka A, Dorsey G, Kamya MR, Talisuna A, Lugemwa M, Rwakimari JB, et al. Artemether-Lumefantrine versus Dihydroartemisinin-Piperaquine for treating uncomplicated malaria: a randomized trial to guide policy in Uganda. PLoS One. 2008;3(6):e2390. https://doi.org/10.1371/journal.pone.0002390. 18545692

59. Juma EA, Obonyo CO, Willis S, Akhwale WS, Ogutu BR. A randomized, openlabel, comparative efficacy trial of Artemether-lumefantrine suspension versus Artemether-lumefantrine tablets for treatment of uncomplicated Plasmodium falciparum malaria in children in western Kenya. Malar J. 2008;7:262.

60. Falade C, Manyando C. Safety profile of Coartem: the evidence base. Malar J. 2009;8(Suppl 1):S6.

61. Mugittu K, Adjuik M, Snounou G, Ntoumi F, Taylor W, Mshinda H, et al. Molecular genotyping to distinguish between recrudescents and new infections in treatment trials of Plasmodium falciparum malaria conducted in sub-Saharan Africa: adjustment of parasitological outcomes and assessment of genotyping effectiveness. Tropical Med Int Health. 2006;11:1350-9.

\section{Submit your next manuscript to BioMed Central and we will help you at every step:}

- We accept pre-submission inquiries

- Our selector tool helps you to find the most relevant journal

- We provide round the clock customer support

- Convenient online submission

- Thorough peer review

- Inclusion in PubMed and all major indexing services

- Maximum visibility for your research

Submit your manuscript at www.biomedcentral.com/submit
Biomed Central 